OPEN ACCESS

Edited by:

Mahua Dey,

University of Wisconsin-Madison,

United States

Reviewed by:

Matteo Zoli,

IRCCS Institute of Neurological

Sciences of Bologna (ISNB), Italy

Paweł Sokal,

Nicolaus Copernicus University in

Toruń, Poland

*Correspondence:

Xin $\mathrm{Li}$

lixinliaocheng@163.com

†These authors have contributed equally to this work and share first authorship

Specialty section

This article was submitted to Neuro-Oncology and Neurosurgical

Oncology,

a section of the journal

Frontiers in Neurology

Received: 06 October 2020 Accepted: 23 February 2021 Published: 23 March 2021

Citation:

Guo S, Wang Z, Kang X, Xin W and

Li X (2021) A Meta-Analysis of Endoscopic vs. Microscopic

Transsphenoidal Surgery for

Non-functioning and Functioning Pituitary Adenomas: Comparisons of

Efficacy and Safety.

Front. Neurol. 12:614382.

doi: 10.3389/fneur.2021.614382

\section{A Meta-Analysis of Endoscopic vs. Microscopic Transsphenoidal Surgery for Non-functioning and Functioning Pituitary Adenomas: Comparisons of Efficacy and Safety}

\author{
Shengfu Guo ${ }^{1+}$, Zidong Wang ${ }^{1 \dagger}$, Xiaokui Kang ${ }^{1}$, Wenqiang Xin ${ }^{2,3}$ and Xin $\mathrm{Li}^{1 *}$ \\ 'Department of Neurosurgery, Liaocheng People's Hospital, Liaocheng, China, ${ }^{2}$ Department of Neurology, University \\ Medical Center Goettingen, Göttingen, Germany, ${ }^{3}$ Department of Neurosurgery, Tianjin Medical University General Hospital, \\ Tianjin, China
}

Background: Although microscopic (MTSS) and endoscopic transsphenoidal surgery (ETSS) are both effective approaches for treating non-functioning pituitary adenomas (NFPA) and functioning pituitary adenomas (FPA), the consensus remains unidentified on whether there are differences in the risk of postoperative complications between the two surgical approaches.

Method: A meta-analysis of the study of MTSS vs. ETSS for NFPA and FPA was conducted by searching the electronic databases of PubMed, Cochrane Library, and EMBASE, from the date of establishment of electronic databases to September 2020 based on the PRISMA guidelines.

Results: In this study, a total of 16 studies were selected, hailing from Belgium, the USA, India, Finland, France, Korea, Spain, China, and Canada. We enrolled 1003 patients in the ETSS and 992 patients in the MTSS group. In patients with NFPA, the ETSS group was related to a higher incidence of post-operative gross-total resection (GTR). (OR = $1.655,95 \% \mathrm{Cl} 1.131-2.421, P=0.010)$. In participants with FPA, the results illustrated that the ETSS group had higher rates of visual improvement $(\mathrm{OR}=2.461,95 \% \mathrm{Cl} 1.109$ 5.459) and gross-total resection ( $\mathrm{OR}=2.033,95 \% \mathrm{Cl} 1.335-3.096)$, as well as lower meningitis rates $(\mathrm{OR}=0.195,95 \% \mathrm{Cl} 0.041-1.923)$. In participants with acromegaly, no significant difference was shown in the postoperative complications.

Conclusion: Based on current evidence, participants with NFPA treated by endoscopy were related to higher rates of GTR; patients with FPA treated by ETSS were related to higher rates of visual improvement and GTR, as well as a lower rates of meningitis.

Keywords: pituitary adenoma, non-functioning, functioning, endoscopic, microscopic 


\section{INTRODUCTION}

Pituitary adenomas, which contribute to $14 \%$ of primary intracranial neoplasms, are the second most common central nervous system tumor. The incidence of pituitary adenomas in the general population has increased to $17 \%(1,2) .36-54 \%$ of pituitary adenomas are non-functional, while $46-64 \%$ of them are hormone-secreting (3-5). Even though a large proportion of pituitary adenomas are histologically benign, due to their location being close to crucial structures and the hypersecretion or paracrisis of the pituitary hormone, they can result in serious endocrine conditions, such as acromegaly and Cushing disease (6).

In the 1960s, Hardy (7) reported an operative microscope for better visualization during transsphenoidal surgery, which enabled the safer removal of sellar tumors. Microscopic transsphenoidal pituitary surgery (MTSS) had at the time been widely performed and became the gold standard. But within the next few years, and with the evolution of endoscopic techniques, by 1992, Jankowski et al. (8) performed fully endoscopic surgery via the endonasal approach for pituitary tumors. Since then, endoscopic transsphenoidal pituitary surgery (ETSS) has increasingly been adopted. Nevertheless, establishing which surgical method is superior in managing pituitary tumors, remains unknown. ETSS enjoys more popularity, attributed to the panoramic view of its surrounding structures and minimal invasiveness, leading to a greater chance of removing central skull base lesions $(9,10)$. Whereas, ETSS has limitations of two-dimensioned visualization, less focus capacity, and a steep learning curve for neurosurgeons. Furthermore, consensus on whether there are differences in the risk of postoperative complications between the two surgical approaches remains unclear (11).

Recently, several studies on ETSS vs. MTSS has been reported in the literature. We thus set out to perform a meta-analysis to evaluate the postoperative outcomes between ETSS and MTSS, in participants with non-functioning pituitary adenomas (NFPA) or functioning pituitary adenomas (FPA).

\section{MATERIALS AND METHODS}

The systematic review and meta-analysis of the literature was performed based on the Preferred Reporting Items for Systematic Reviews and Meta-Analyses (PRISMA) (12).

\section{Literature Search}

The search object was research literature on the analysis of all comparative studies of ETSS vs. MTSS for non-functioning and functioning pituitary adenomas published in publicly available electronic databases, including PubMed, Cochrane Library, and EMBASE, from the date of establishment of electronic

Abbreviations: MTSS, microscopic transsphenoidal pituitary surgery; GTR, Gross-total resection; NFPA, non-functioning Pituitary Adenomas; FPA, Functioning Pituitary Adenomas; ETSS, endoscopic transsphenoidal pituitary surgery; Cis, confidence intervals; WMD, weighted mean differences; CSF, cerebrospinal fluid; RDs, rate differences; ORs, odds ratios; PRISMA, Preferred Reporting Items for Systematic Reviews and Meta-Analyses.
TABLE 1 | The search strategy for studies comparing endoscopic vs. microscopic transsphenoidal surgery.

Transsphenoidal surgery OR Neurologic surgical procedure OR

Neuroendoscopy OR Microsurgery

AND

Pituitary OR Pituitary and surgery OR Pituitary adenomas OR Pituitary neoplasm

AND

(Non-functioning OR Functioning

OR

Acromegaly OR GH-secreting adenoma OR GH-producing adenoma OR Somatotroph tumor)

databases to September 2020. To obtain maximum results in identifying relevant literature, the following literature search keywords were adopted: "transsphenoidal surgery," "pituitary," "non-functioning," "functioning," “endoscopic," "microsurgical," and "acromegaly." The specific search strategy for publications comparing endoscopic vs. microscopic transsphenoidal surgery is shown in Table 1. Furthermore, the reference lists of relevant studies and reviews were manually checked by two authors, to further identify other potential studies in the literature.

\section{Inclusion and Exclusion Criteria}

The study selection was in accordance with the following PICOS criteria: (I) population: strictly refers to the NFPA or FPA; (II) intervention: ETSS and MTSS; (III) comparison: the outcomes of procedure-related efficacy and safety; (IV) outcome measures: reports one or more of the including endpoints: gross-total resection (GTR), cerebrospinal fluid (CSF) leak, length of stay, visual improvement, hypothyroidism, meningitis, hematoma, operation time, diabetes insipidus, hypopituitarism, hypocortisolism, and mortality; and (V) the full-text of publications were written in English.

Our exclusion criteria are: (I) studies that lack details of postoperative efficacy or complications; (II) studies with an imbalance of clinical characteristics; (III) non-investigative studies like case report, case series, and single-armed studies; (III) conference proceedings, letters, animal trials, systematic reviews, and meta-analyses.

\section{Data Extraction}

We assigned three authors to extract information of included studies, respectively. Two authors extracted all study design details from the full text of the included study, then the third author checked all extracted data. Discrepancies were resolved by consulting clinical experts. For each included study, the following details were extracted: study characteristics (first author, year of publication, country, sample size, study type), case characteristics (sex and age), and operation type. The following outcome items were also extracted: GTR, length of stay, diabetes insipidus, visual improvement, CSF leak, hypothyroidism, hypopituitarism, meningitis, hematoma, hypocortisolism, operation time, and mortality. 


\section{Statistical Analysis}

Comparisons of the postoperative complications after ETSS and MTSS were analyzed by the standard software STATA version 12.0. Heterogeneity among studies was assessed using Cochran's Q-test $(p<0.10)$ and the $I^{2}$-value. In brief, when the $I^{2}>$ $50 \%$, we considered the heterogeneity to be high, and a randomeffect model would be selected. Otherwise, a fixed-effect model was selected. As for continued variables, the length of stay and operation time were expressed as weighted mean differences (WMD) with 95\% confidence intervals (CIs). For the binary variables, the odds ratios (ORs) or rate differences (RDs) with 95\% CIs were applied for assessment. A $p<0.05$ was considered to be statistically significantly different.

\section{RESULTS}

\section{Search Results}

The initial search resulted in 3,412 English-language full-text studies from the electronic databases of PubMed, Cochrane Library, and EMBASE. Two-thousand-and-thirty-five of the articles were removed as a result of duplicates. One-thousandone-hundred-and-sixty-six articles were deleted by screening the title and abstract based on the inclusion and exclusion criteria. The remaining 211 studies were used for full-text screening. Finally, 16 articles were selected for our final analysis, including 1003 patients who underwent ETSS, and 992 patients who underwent MTSS. Seven articles directly compared the two interventions for NFPA, Seven for FPA, while three articles compared the two groups for acromegaly. Figure $\mathbf{1}$ describes this in more detail.

\section{Methodological Quality Assessment}

In this study, the Newcastle-Ottawa Scale (NOS) was adopted to assess the quality of all observational studies with a score range between $0 \sim 9$. Two authors (SFG and ZDW) evaluated the quality of the included literature independently. When differences arose in this process, the authors would discuss. All included articles were of high quality, and more details about the quality assessment of the included studies are shown in Table 2.

\section{Study Characteristics}

In this study, a total of 16 studies $(10,11,13-26)$ were included, hailing from Belgium, the USA, India, Finland, France, Korea, Spain, China, and Canada. We enrolled 1003 patients in the ETSS and 992 patients in the MTSS group. Patients with pituitary adenomas were divided into non-functional (775 patients), functional (687 patients), and acromegaly (291 patients) groups. In the NPFA patients, there were seven articles including 994 patients. Of those 994 NFPA participants, 484 belonged to the endoscopic group vs. 510 to the microscopic group. In FPA patients, there were Seven articles including 775 cases. Among those 775 FPA cases, 381 belonged to endoscopic treatment vs. 394 to microscopic treatment. As for the acromegaly group, there were Three articles including 291 participants. More information about the study characteristics is shown in Table 3.

\section{Outcomes}

\section{Analyzed Items}

The items analyzed in this study were: (1) the GTR, based on postoperative imaging confirming tumor absence; (2) the time of operation and length of stay for two surgery; and (3) postoperative complications (visual improvement, CSF leak, diabetes insipidus, hypothyroidism, hypocortisolism, meningitis, hematoma, hypopituitarism, and mortality). More information is shown in Table 4.

\section{Comparison of Two Interventions for Treating Non-functioning Pituitary Adenomas \\ Gross-Total Resection (GTR)}

We adopted meta-analytical techniques to assess the incidence of postoperative GTR. Reviewing the data of the included studies, five publications (250 endoscopic and 383 microscopic) reported on the postoperative GTR. We selected the fixed effects model because the heterogeneity was not significantly different $(P=$ $\left.0.206, I^{2}=32.3 \%\right)$. The ETSS group was related to a higher incidence of postoperative GTR in NFAP participants (OR = $1.655,95 \%$ CI 1.131-2.421, $P=0.010$, Figure 2).

\section{Length of Stay}

Three studies (288 endoscopic, 205 microscopic) reported data on length of stay. We found that the difference between the two surgeries was not statistically significant $(\mathrm{WMD}=0.112,95 \% \mathrm{CI}$ -0.791 to $1.014, P=0.808)$.

\section{Postoperative Complications}

The pooled estimates of the overall proportions showed no significant difference in the incidence of visual improvement (OR $=3.636, P=0.147)$, diabetes insipidus $(\mathrm{OR}=1.033, P=0.903$, Figure 3), hypocortisolism $(\mathrm{OR}=0.640, P=0.562)$, hematoma $(\mathrm{OR}=0.788, P=0.645)$, CSF leak $(\mathrm{RD}=-0.01, P=0.506$, Figure 4), hypopituitarism ( $\mathrm{OR}=0.753, P=0.315)$, meningitis $(\mathrm{RD}=-0.004, P=0.653)$, hypothyroidism $(\mathrm{OR}=0.582, P=$ $0.169)$, and mortality ( $\mathrm{RD}=-0.001, P=0.958)$ according to the data of seven studies.

\section{Comparison of Two Interventions for Treating Functioning Pituitary Adenomas Gross-Total Resection (GTR)}

Five publications (229 endoscopic, 244 microscopic) reported on the postoperative GTR. A fixed-effects model was used to assess this, due to no significant heterogeneity $\left(P=0.302, I^{2}=17.6 \%\right)$. The GTR rate was $73.8 \%$ in the endoscopic group and $62.3 \%$ in the microscopic group. The pooled evaluation of the overall proportions demonstrated that a significantly higher rate of GTR appeared in the ETSS group (OR $=2.033,95 \%$ CI 1.335-3.096, $P$ $=0.001$, Figure 5).

\section{Time of Operation and Length of Stay}

Three studies (228 endoscopic, 251 microscopic) reported data on length of stay. We found that the difference was not statistically significant between the two groups (WMD $=-1.284$, $95 \%$ CI -3.656 to $1.089, P=0.289$ ). Similarly, the results 

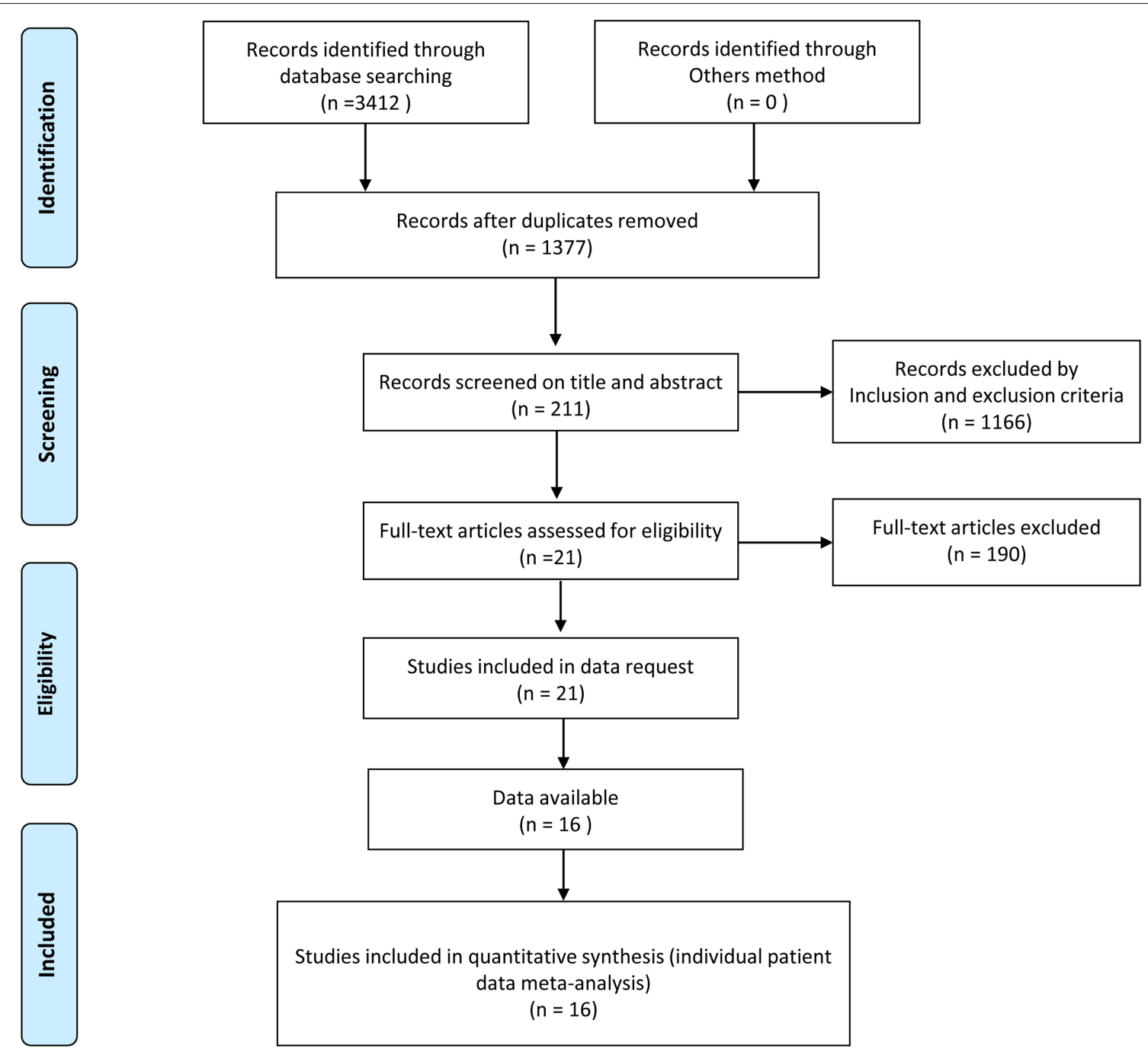

FIGURE 1 | Flowchart of the study selection process.

showed that there was no significant difference found in the operation time (WMD $=4.022,95 \%$ CI -53.674 to 61.719, $P=0.891)$.

\section{Postoperative Complications}

Four studies reported data on meningitis. No significant heterogeneity was found, then the fixed effects model was selected $\left(P=0.998, I^{2}=0 \%\right)$. We found that endoscopic treatment was related to lower meningitis rates than in the microscopic group (OR $=0.195,95 \%$ CI 0.041-1.923, $P=0.039$, Figure 6). Furthermore, endoscopic treatment had a higher incidence of visual improvement $(\mathrm{OR}=2.461,95 \% \mathrm{CI} 1.109-5.459, P=$ 0.027 , Figure 7). However, according to the data of six studies, a significant difference was not found between the two groups for diabetes insipidus ( $\mathrm{RD}=-0.136, P=0.145)$, hypocortisolism $(\mathrm{OR}=0.675, P=0.343)$, hematoma $(\mathrm{RD}=0.015, P=0.440)$, CSF leak $(\mathrm{OR}=1.054, P=0.880)$, and mortality $(\mathrm{RD}=0.000$, $P=1.000)$.

\section{Comparison of Two Interventions for Treating Acromegaly Postoperative Complications}

The pooled estimates of the overall proportions showed that the incidence of CSF leak ( $\mathrm{OR}=0.581, P=0.404)$, hypopituitarism $(\mathrm{OR}=1.214, P=0.646)$, diabetes insipidus $(\mathrm{OR}=0.905$, $P=0.896)$, hypothyroidism ( $\mathrm{OR}=0.576, P=0.244)$, and hypocortisolism $(\mathrm{OR}=0.703, P=0.709)$ was not significantly different between the two groups based on the data of three studies.

\section{DISCUSSION}

\section{Summarizing the Objectives and Main Findings}

The current common operations for pituitary adenomas are ETSS and MTSS. Although the merits and disadvantages of ETSS 
TABLE 2 | The literature quality assessment.

\begin{tabular}{|c|c|c|c|c|c|}
\hline \multirow[t]{2}{*}{ References } & \multirow[t]{2}{*}{ Design } & \multicolumn{4}{|c|}{ Newcastle-Ottawa scale (NOS) } \\
\hline & & Selection & Comparability & Exposure & Total scores \\
\hline Sheehan et al. (13) & Retrospective cohort study & 2 & 2 & 2 & 6 \\
\hline Messerer et al. (14) & Retrospective cohort study & 4 & 1 & 2 & 7 \\
\hline Dallapiazza et al. (15) & Retrospective cohort study & 3 & 2 & 3 & 8 \\
\hline Karppinen et al. (16) & Retrospective cohort study & 3 & 1 & 2 & 6 \\
\hline Zaidi et al. (10) & Retrospective cohort study & 3 & 1 & 3 & 7 \\
\hline Pledger et al. (25) & Retrospective cohort study & 4 & 2 & 2 & 8 \\
\hline Little et al. (17) & Prospective cohort study & 4 & 2 & 3 & 9 \\
\hline Haens et al. (26) & Retrospective cohort study & 3 & 1 & 2 & 6 \\
\hline Choe et al. (18) & Retrospective cohort study & 4 & 2 & 2 & 8 \\
\hline Cheng et al. (19) & Retrospective cohort study & 3 & 2 & 2 & 7 \\
\hline Fathalla et al. (20) & Retrospective cohort study & 4 & 1 & 3 & 8 \\
\hline Gao et al. (21) & Retrospective cohort study & 3 & 1 & 3 & 7 \\
\hline Guo-Dong et al. (22) & Retrospective cohort study & 3 & 1 & 2 & 6 \\
\hline Starke et al. (23) & Retrospective cohort study & 3 & 2 & 2 & 7 \\
\hline Sarkar et al. (24) & Retrospective cohort study & 3 & 2 & 2 & 7 \\
\hline Castaño-Leon et al. (11) & Prospective cohort study & 4 & 2 & 2 & 8 \\
\hline
\end{tabular}

NOS, Newcastle-Ottawa scale.

TABLE 3 | Characteristics of publication year, country, study type, cases, and gender (Female/Male) in each group for included studies.

\begin{tabular}{|c|c|c|c|c|c|c|c|c|c|c|}
\hline \multirow[t]{2}{*}{ Author } & \multirow[t]{2}{*}{ Country } & \multirow[t]{2}{*}{ Years } & \multirow[t]{2}{*}{ Type of study } & \multicolumn{2}{|c|}{ Sample size $(n)$} & \multicolumn{2}{|c|}{ Gender (F/M) } & \multicolumn{2}{|c|}{ Age (mean \pm standard) } & \multirow[t]{2}{*}{ NOS } \\
\hline & & & & Endoscopy & Microscopy & Endoscopy & Microscopy & Endoscopy & Microscopy & \\
\hline \multicolumn{11}{|c|}{ Comparison of two intervention for treating non-functioning pituitary adenomas } \\
\hline Sheehan et al. & USA & 1999 & Retrospective & 26 & 44 & $8 / 18$ & $13 / 31$ & $59.2 \pm 15.1$ & $57.8 \pm 14.9$ & 6 \\
\hline Messerer et al. & France & 2011 & Retrospective & 82 & 82 & $35 / 47$ & $31 / 51$ & $57.0(20-82)$ & $56.5(27-84)$ & 7 \\
\hline Dallapiazza et al. & USA & 2014 & Retrospective & 56 & 43 & $19 / 24$ & $29 / 27$ & $56.7 \pm 16.9$ & $56.2 \pm 12.8$ & 8 \\
\hline Karppinen et al. & Finland & 2015 & Retrospective & 41 & 144 & $18 / 23$ & $49 / 95$ & $58.4(17-83)$ & $58.5(16-86)$ & 6 \\
\hline Zaidi et al. & USA & 2016 & Retrospective & 55 & 80 & $20 / 35$ & $30 / 50$ & $55.9 \pm 13.8$ & $59.1 \pm 14.6$ & 7 \\
\hline Pledger et al. & USA & 2015 & Retrospective & 47 & 35 & $24 / 23$ & $18 / 17$ & 52 (32.5-79.5) & $54(27-74)$ & 8 \\
\hline Little et al. & USA & 2019 & Prospective & 177 & 82 & 73/104 & $30 / 52$ & $58.6 \pm 13.3$ & $58.1 \pm 14.0$ & 9 \\
\hline \multicolumn{11}{|c|}{ Comparison of two intervention for treating functioning pituitary adenomas 6} \\
\hline Haens et al. & Belgium & 2008 & Retrospective & 60 & 60 & $41 / 19$ & $16 / 44$ & $837(10-70)$ & $35(10-68)$ & 6 \\
\hline Choe et al. & Korea & 2008 & Retrospective & 12 & 11 & $7 / 5$ & $9 / 2$ & $47 \pm 12$ & $48 \pm 10$ & 8 \\
\hline Cheng et al. & China & 2011 & Retrospective & 68 & 59 & $37 / 31$ & $39 / 20$ & $37.82(13-69)$ & $33.8(11-71)$ & 7 \\
\hline Fathalla et al. & Canada & 2015 & Retrospective & 42 & 23 & $21 / 21$ & $16 / 7$ & 43.2 & 42.1 & 8 \\
\hline Gao et al. & China & 2016 & Retrospective & 60 & 45 & $34 / 26$ & $26 / 19$ & $44.6(19-75)$ & $48.8(21-77)$ & 7 \\
\hline Guo-dong et al. & China & 2016 & Retrospective & 100 & 147 & $41 / 59$ & $94 / 53$ & $43.4 \pm 14.0$ & $40.4 \pm 14.2$ & 6 \\
\hline Castaño-Leon et al. & Spain & 2020 & Prospective & 39 & 49 & NA & NA & NA & NA & 8 \\
\hline \multicolumn{11}{|c|}{ Comparison of two intervention for treating acromegaly } \\
\hline Starke et al. & USA & 2013 & Retrospective & 72 & 41 & $40 / 32$ & $21 / 20$ & $49.2 \pm 14.9$ & $47.5 \pm 14.2$ & 7 \\
\hline Sarkar et al. & India & 2014 & Retrospective & 66 & 47 & $36 / 30$ & $21 / 26$ & $37.6 \pm 10.8$ & $38.7 \pm 12.2$ & 7 \\
\hline Fathalla et al. & Canada & 2015 & Retrospective & 42 & 23 & $21 / 21$ & $16 / 7$ & 43.2 & 42.1 & 8 \\
\hline
\end{tabular}

NA, not available; F, female; M, male; NOS, Newcastle-Ottawa Scale.

vs. MTSS for treating pituitary adenoma have been assessed previously, the comparisons of two interventions, specifically on NFPA and FPA, have never been comprehensive and systematically performed before. Previous meta-analyses do not include a purely comparative study to evaluate the efficacy and safety between the two interventions, resulting in their ability to provide certain evidence for intervention remaining controversial. Thus, we conducted this meta-analysis to explore 
TABLE 4 | The postoperative outcomes of this meta-analysis.

\begin{tabular}{|c|c|c|c|c|c|c|c|c|}
\hline \multirow[t]{2}{*}{ Outcomes } & \multirow[t]{2}{*}{ Studies numbers } & \multicolumn{2}{|c|}{ Groups size } & \multicolumn{3}{|c|}{ Overall effect } & \multicolumn{2}{|c|}{ Heterogeneity } \\
\hline & & Endoscopic & Microscopic & Effect estimate & $95 \% \mathrm{Cl}$ & $P$-value & $I^{2}(\%)$ & $P$-value \\
\hline \multicolumn{9}{|c|}{ Comparison of two interventions for treating non-functioning pituitary adenomas } \\
\hline Gross-total resection & 5 & 250 & 383 & OR, 1.655 & $1.131,2.421$ & 0.010 & $32.3 \%$ & 0.206 \\
\hline CSF leak & 7 & 472 & 510 & $\mathrm{RD},-0.010$ & $-0.041,0.020$ & 0.506 & $0.0 \%$ & 0.916 \\
\hline Diabetes insipidus & 6 & 339 & 559 & OR, 1.033 & $0.610,1.751$ & 0.903 & $32.5 \%$ & 0.192 \\
\hline Visual improvement & 2 & 69 & 93 & OR, 3.636 & $0.634,20.849$ & 0.147 & $0.0 \%$ & 0.366 \\
\hline Meningitis & 4 & 355 & 388 & $\mathrm{RD},-0.004$ & $-0.024,0.015$ & 0.653 & $0.0 \%$ & 0.942 \\
\hline Hematoma & 5 & 381 & 432 & OR, 0.788 & $0.286,2.169$ & 0.645 & $35.5 \%$ & 0.185 \\
\hline Hypopituitarism & 4 & 171 & 244 & OR, 0.753 & $0.433,1.309$ & 0.315 & $13.2 \%$ & 0.327 \\
\hline Hypothyroidism & 2 & 152 & 103 & OR, 0.582 & $0.269,1.259$ & 0.169 & $0.0 \%$ & 0.773 \\
\hline Hypocortisolism & 3 & 246 & 182 & OR, 0.640 & $0.142,2.890$ & 0.562 & $82.7 \%$ & 0.003 \\
\hline Total mortality & 2 & 259 & 164 & $\mathrm{RD},-0.001$ & $-0.020,0.019$ & 0.958 & $0.0 \%$ & 0.960 \\
\hline Length of Stay & 3 & 288 & 205 & WMD, 0.112 & $-0.791,1.014$ & 0.808 & $61.2 \%$ & 0.076 \\
\hline \multicolumn{9}{|c|}{ Comparison of two interventions for treating functioning pituitary adenomas } \\
\hline Gross-total resection & 5 & 229 & 244 & OR, 2.033 & $1.335,3.096$ & 0.001 & $17.6 \%$ & 0.302 \\
\hline CSF leak & 6 & 342 & 345 & OR, 1.054 & $0.535,2.076$ & 0.880 & $0.0 \%$ & 0.445 \\
\hline Diabetes insipidus & 6 & 341 & 237 & $\mathrm{RD},-0.136$ & $-0.319,0.047$ & 0.145 & $96.7 \%$ & 0.000 \\
\hline Visual improvement & 3 & 71 & 54 & OR, 2.461 & $1.109,5.459$ & 0.027 & $25.6 \%$ & 0.261 \\
\hline Meningitis & 4 & 232 & 263 & OR, 0.195 & $0.041,1.923$ & 0.039 & $0.0 \%$ & 0.998 \\
\hline Hematoma & 2 & 112 & 158 & $\mathrm{RD}, 0.015$ & $-0.023,0.053$ & 0.440 & $0.0 \%$ & 0.838 \\
\hline Hypopituitarism & 5 & 282 & 285 & OR, 0.675 & $0.299,1.521$ & 0.343 & $48.4 \%$ & 0.101 \\
\hline Total mortality & 2 & 120 & 105 & $\mathrm{RD}, 0.000$ & $-0.025,0.025$ & 1.000 & $0.0 \%$ & 1.000 \\
\hline Length of Stay & 3 & 228 & 251 & WMD, -1.284 & $-3.656,1.089$ & 0.289 & $95 \%$ & 0.000 \\
\hline Operation time & 4 & 325 & 336 & WMD, 4.022 & $-53.674,61.719$ & 0.891 & $99.0 \%$ & 0.000 \\
\hline \multicolumn{9}{|c|}{ Comparison of two interventions for treating acromegaly } \\
\hline CSF leak & 3 & 181 & 111 & OR, 0.581 & $0.163,2.079$ & 0.404 & $0.0 \%$ & 0.791 \\
\hline Diabetes insipidus & 3 & 179 & 111 & OR, 0.905 & $0.203,4.029$ & 0.896 & $68.4 \%$ & 0.042 \\
\hline Hypopituitarism & 2 & 108 & 70 & OR, 1.214 & $0.531,2.77$ & 0.646 & $0.0 \%$ & 0.368 \\
\hline Hypothyroidism & 2 & 136 & 86 & OR, 0.576 & $0.228,1.457$ & 0.244 & $0.0 \%$ & 0.560 \\
\hline Hypocortisolism & 2 & 132 & 87 & OR, 0.703 & $0.111,4.476$ & 0.709 & $77.8 \%$ & 0.034 \\
\hline
\end{tabular}

Cls, confidence intervals; $R D$, rate difference; OR, odds ratio; CSF, Cerebrospinal fluid. Bold values means $P<0.05$.

whether there were any differences in the risk of postoperative complications between the two groups in cases with NFPA or FPA. This quantitative analysis included 1995 patients with pituitary adenoma assessed in 16 studies, and this pooled data showed that FPA or NFPA patients treated by ETSS, had a higher incidence rate of GTR.

\section{MTSS Had a Higher Rate of GTR in Patients With NFPA or FPA}

In this meta-analysis, the pooled statistic revealed that the NFPA participants treated with endoscopes had a higher incidence of GTR $(\mathrm{OR}=1.655,95 \%$ CI 1.131-2.421, $P=0.010)$. Likewise, a meta-analysis conducted by Gao et al. (27) found that the higher incidence of GTR appeared to be in patients treated with ETSS rather than those treated by MTSS $(P=0.0001)$, consistent with the study conducted by Yu et al. (28) $(P<$ $0.001)$ Similarly, we also revealed that the proportion of GTR was also relatively higher in FPA cases treated by ETSS compared to patients treated by MTSS (OR $=2.033$, 95\% CI $1.335-$ 3.096, $P=0.001)$. Parasellar extension accounted for most resection outcomes, with a panoramic view where endoscopy provides a wider and superior route to parasellar and suprasellar compartments, contributing to the higher rates of GTR (29). In brief, the endoscope is particularly useful in obtaining a panoramic view of the surrounding structures through the use of angled endoscopes.

\section{ETSS Resulted in a Lower Incidence of Meningitis and a High Incidence of Visual Improvement}

Beyond what is described above, the lower rates of meningitis in patients with FPA undergoing ETSS was shown by the pooled data $(\mathrm{OR}=0.195,95 \%$ CI 0.041-1.923, $P=0.039)$. The origin behind the effect might be from the superiorities of ETSS, such as a shorter operation time. Moreover, there was a higher percentage of patients with FPA treated with ETSS who gained visual improvement $(\mathrm{OR}=2.461,95 \% \mathrm{CI}$ 
Study

ID
$\%$

OR $(95 \% \mathrm{Cl}) \quad$ Weight

\begin{tabular}{|c|c|c|}
\hline Sheehan et al. (1999) & $1.09(0.33,3.58)$ & 12.53 \\
\hline Messerer et al. (2011) & $2.90(1.50,5.61)$ & 25.33 \\
\hline Dallapiazza et al. (2014) & $2.03(0.32,12.69)$ & 3.90 \\
\hline Karppinen et al. (2015) & $1.56(0.77,3.14)$ & 30.37 \\
\hline Zaidi et al. (2016) & $0.83(0.35,1.94)$ & 27.88 \\
\hline Overall $(I$-squared $=32.3 \%, p=0.206$ ) & $1.65(1.13,2.42)$ & 100.00 \\
\hline .0788 & 12.7 & \\
\hline
\end{tabular}

FIGURE 2 | Forest plot on gross-total resection with ETSS vs. MTSS for NFPA.

Study

ID
$\%$

OR $(95 \% \mathrm{Cl}) \quad$ Weight
Sheehan et al. (1999)

Messerer et al. (2011)

Dallapiazza et al. (2014)

Zaidi et al. (2016)

Karppinen et al. (2015)

Little et al. (2019)

Overall (I-squared $=32.5 \%, p=0.192$ )

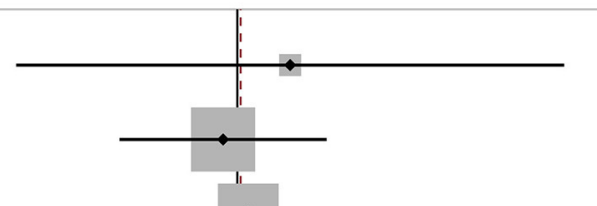

$1.72(0.10,28.72)$

$0.86(0.30,2.50) \quad 26.98$

$1.12(0.39,3.23) \quad 23.98$

$0.19(0.02,1.62) \quad 20.64$

$0.62(0.13,2.92) \quad 17.10$

$3.94(1.12,13.87) \quad 8.67$

$1.03(0.61,1.75) \quad 100.00$

\section{1}

43.3

FIGURE 3 | Forest plot on diabetes insipidus with ETSS vs. MTSS for NFPA. 
Study

ID
$\%$

$\operatorname{RD}(95 \% \mathrm{Cl}) \quad$ Weight

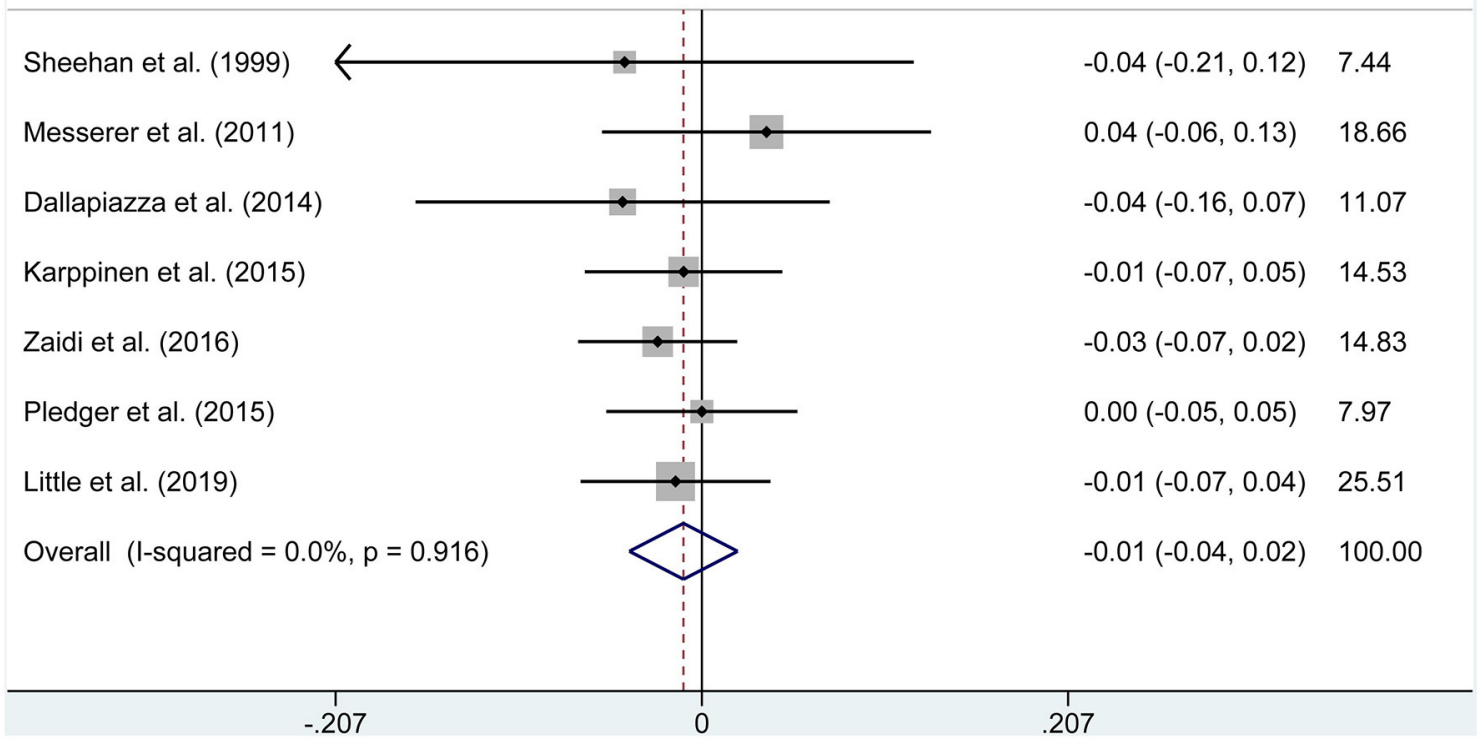

FIGURE 4 | Forest plot on cerebrospinal fluid leak with ETSS vs. MTSS for NFPA.

Study

ID
$\%$

OR $(95 \% \mathrm{Cl}) \quad$ Weight

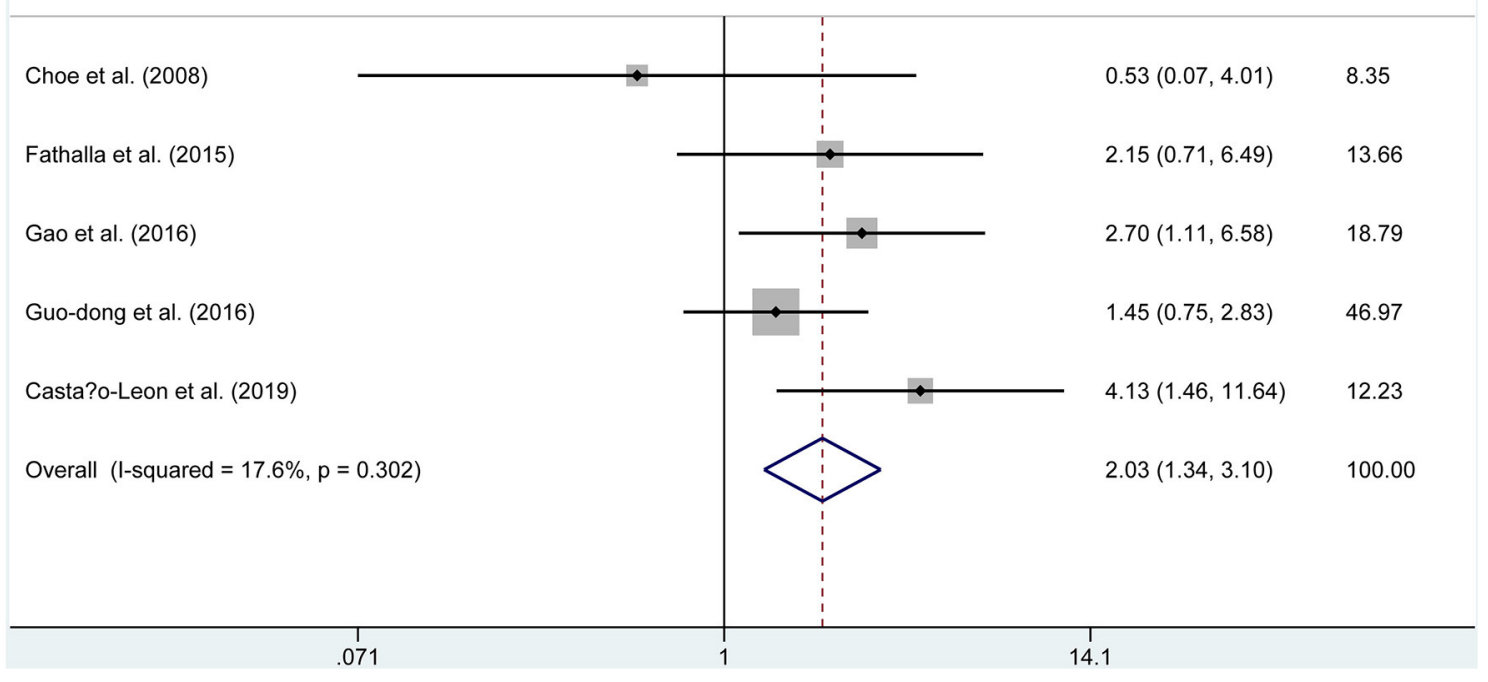

FIGURE 5 | Forest plot on gross-total resection with ETSS vs. MTSS for FPA. 
Study

ID
$\%$

OR $(95 \% \mathrm{Cl}) \quad$ Weight

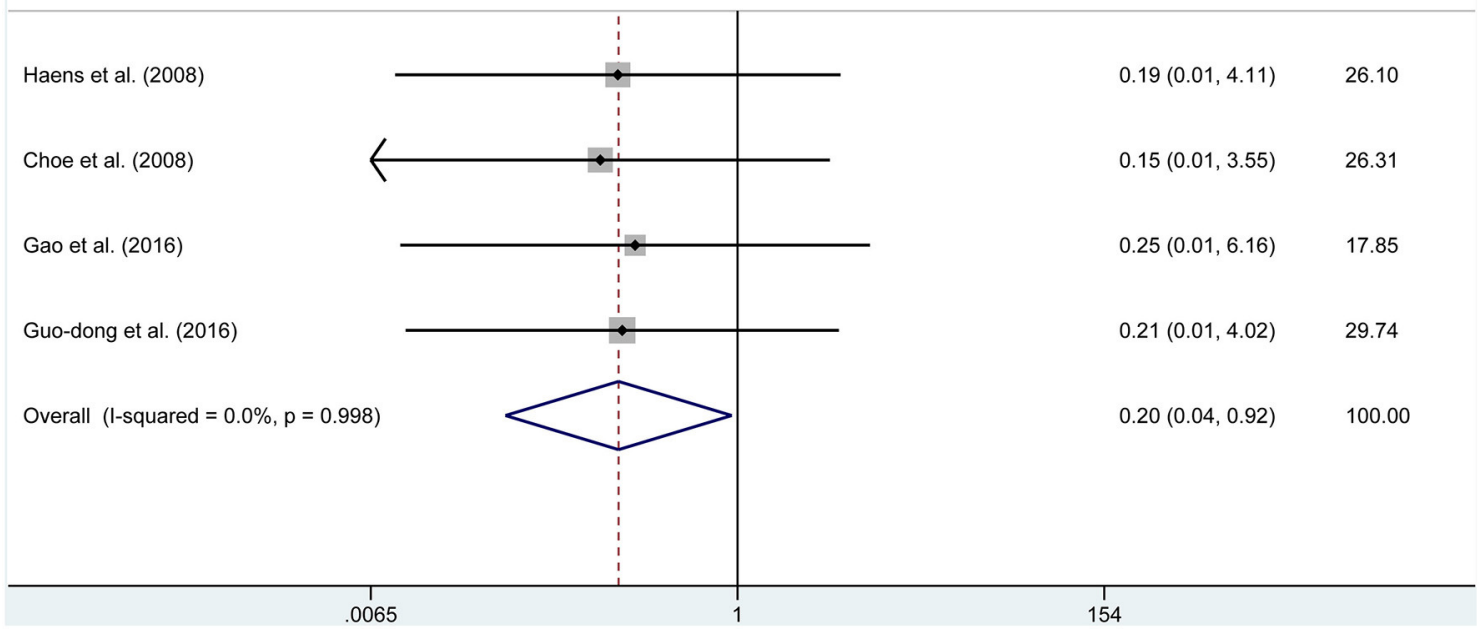

FIGURE 6 | Forest plot on meningitis with ETSS vs. MTSS for FPA.



FIGURE 7 | Forest plot on visual improvement with ETSS vs. MTSS for FPA.

1.109-5.459, $P=0.027$ ). ETSS has been proven to be more capable of exploring sella turcica with a panoramic view, which increases the success incidence and fully eliminates compression on optic chiasma due to sellar region lesions. Concerning patients with acromegaly, ETSS and MTSS demonstrated no statistically significant difference in controlling postoperative 
complications, which might be caused by the shortage of data extracted from only three included studies. With an increase in highly-qualified studies related to surgical treatment of acromegaly reported in the future, results of significance may yet be revealed.

\section{ETSS Did Not Lead to the Higher Rates of Postoperative Complications Such as CSF Leak and Diabetes Insipidus}

There was no significant difference in the CSF leak and diabetes insipidus between the two modalities, irrespective of being NFPA or FPA patients. Reconstructive procedures following resection should be acknowledged as an essential factor for the risk of a postoperative leak of CSF (30). Theoretically, reconstruction performed with the endoscope, offering wider visualization, enjoyed a higher success rate. This would reduce the incidence of CSF leakage for patients treated by MTSS to some extent. Whereas, in this study, the discrepant incidence of postoperative CSF leaks was of no statistical significance. The main cause for this might be that elevated exposure during ETSS would result in more aggressive surgical exploration, leading to an increased rate of postoperative CSF leaks. Besides that, a learning curve $(31,32)$ was expected owing to the fact that ETSS was an updated technique, while it was impossible to incorporate a surgeon's level of experience. Thus, although actual complications might be different between ETSS and MTSS, the differences may be neutralized by the above factors. Additionally, a non-significant correlation exists between the lower rates of diabetes insipidus and ETSS when compared to MTSS, despite ETSS acquiring a higher rate of GTR. We suspect that the tumor type might play a key role in this effect (29), whereas no stratified results were described for most included trials to help us conduct a subgroup analysis.

\section{Study Limitations}

This study had some limitations; (I) a great many of the related comparative articles were excluded from this articles due to the

\section{REFERENCES}

1. Dolecek TA, Propp JM, Stroup NE, Kruchko C. CBTRUS statistical report: primary brain and central nervous system tumors diagnosed in the United States in 2005-2009. Neuro Oncol. (2012) 14 Suppl 5(Suppl 5):v1-49. doi: 10.1093/neuonc/nos218

2. Ezzat S, Asa SL, Couldwell WT, Barr CE, Dodge WE, Vance ML, et al. The prevalence of pituitary adenomas: a systematic review. Cancer. (2004) 101:613-9. doi: 10.1002/cncr.20412

3. Tjörnstrand A, Gunnarsson K, Evert M, Holmberg E, Ragnarsson O, Rosén $\mathrm{T}$, et al. The incidence rate of pituitary adenomas in western Sweden for the period 2001-2011. Eur J Endocrinol. (2014) 171:519-26. doi: 10.1530/EJE-14-0144

4. Raappana A, Koivukangas J, Ebeling T, Pirilä T. Metabolism. incidence of pituitary adenomas in Northern Finland in 19922007. J Clin Endocrinol. (2010) 95:4268-75. doi: 10.1210/jc.20 $10-0537$

5. Agustsson TT, Baldvinsdottir T, Jonasson JG, Olafsdottir E, Steinthorsdottir V, Sigurdsson G, et al. The epidemiology of pituitary adenomas in Iceland, 1955-2012: a nationwide population-based study. Eur J Endocrinol. (2015) 173:655-64. doi: 10.1530/EJE-15-0189 fact that various pituitary adenomas subtypes were involved and where specific information about NFPA or FPA could not be obtained; (II) this study assessed all endpoints with different follow-ups between the two groups, which could cause a bias; (III) although this study used a rigorous search strategy to identify all relevant studies, a small number of studies might have been overlooked; and (IV) microadenomas are different than invasive, cavernous sinus extended macroadenoma, and we were unable to perform a subgroup analysis based on adenoma size and Hardy-Wilson classification, due to the limited data.

\section{CONCLUSION}

Based on current evidence, NFPA patients treated by endoscopy were had higher rates of GTR; FPA patients treated by ETSS had a higher rate of visual improvement and GTR, as well as a lower rate of meningitis.

\section{DATA AVAILABILITY STATEMENT}

The original contributions presented in the study are included in the article/supplementary material, further inquiries can be directed to the corresponding author/s.

\section{AUTHOR CONTRIBUTIONS}

SG and XL designed the study, acquired the data, drafted the article, and analyzed and interpreted the data. ZW and $\mathrm{XK}$ revised the article critically for important intellectual content together. All authors approved the version to be published.

\section{FUNDING}

This work was supported by the Zhao Yichang Incubation Fund Nursing Research Project of Tianjin Medical University General Hospital, No. 303071902801 (Yan Yuan).

6. Beckers A, Aaltonen LA, Daly AF, Karhu A. Familial isolated pituitary adenomas (FIPA) and the pituitary adenoma predisposition due to mutations in the aryl hydrocarbon receptor interacting protein (AIP) gene. Endocrine Rev. (2013) 34:239-77. doi: 10.1210/er.2012-1013

7. Hardy J. The transsphenoidal surgical approach to the pituitary. Hosp Practice. (1979) 14:81-9. doi: 10.1080/21548331.1979.11707562

8. Jankowski R, Auque J, Simon C, Marchal JC, Hepner H, Wayoff M. Endoscopic pituitary tumor surgery. Laryngoscope. (1992) 102:198-202. doi: 10.1288/00005537-199202000-00016

9. Kahilogullari G, Beton S, Al-Beyati ES, Kantarcioglu O, Bozkurt M, Kantarcioglu E, et al. Olfactory functions after transsphenoidal pituitary surgery: endoscopic versus microscopic approach. Laryngoscope. (2013) 123:2112-9. doi: 10.1002/lary.24037

10. Zaidi HA, Awad AW, Bohl MA, Chapple K, Knecht L, Jahnke H, et al. Comparison of outcomes between a less experienced surgeon using a fully endoscopic technique and a very experienced surgeon using a microscopic transsphenoidal technique for pituitary adenoma. J Neurosurg. (2016) 124:596-604. doi: 10.3171/2015.4.JNS15102

11. Castaño-Leon AM, Paredes I, Munarriz PM, Jiménez-Roldán L, Hilario A, Calatayud M, et al. Endoscopic transnasal trans-sphenoidal approach for pituitary adenomas: a comparison to the microscopic approach 
cohort by propensity score analysis. Neurosurgery. (2020) 86:348-56. doi: 10.1093/neuros/nyz201

12. Xin WQ, Xin QQ, Yang XY. Meta-analysis of clipping versus coiling for the treatment of unruptured middle cerebral artery aneurysms: direct comparison of procedure-related complications. Neuropsychiatric Dis Treat. (2019) 15:3387-95. doi: 10.2147/NDT.S2 26353

13. Sheehan MT, Atkinson JL, Kasperbauer JL, Erickson BJ, Nippoldt TB. Preliminary comparison of the endoscopic transnasal vs the sublabial transseptal approach for clinically nonfunctioning pituitary macroadenomas. Mayo Clin Proc. (1999) 74:661-70. doi: 10.4065/74.7.661

14. Messerer M, De Battista JC, Raverot G, Kassis S, Dubourg J, Lapras V, et al. Evidence of improved surgical outcome following endoscopy for nonfunctioning pituitary adenoma removal. Neurosurg Focus. (2011) 30:E11. doi: 10.3171/2011.1.FOCUS10308

15. Dallapiazza R, Bond AE, Grober Y, Louis RG, Payne SC, Oldfield EH, et al. Retrospective analysis of a concurrent series of microscopic versus endoscopic transsphenoidal surgeries for Knosp Grades 0-2 nonfunctioning pituitary macroadenomas at a single institution. J Neurosurg. (2014) 121:5117. doi: 10.3171/2014.6.JNS131321

16. Karppinen A, Kivipelto L, Vehkavaara S, Ritvonen E, Tikkanen E, Kivisaari $\mathrm{R}$, et al. Transition from microscopic to endoscopic transsphenoidal surgery for nonfunctional pituitary adenomas. World Neurosurg. (2015) 84:48-57. doi: 10.1016/j.wneu.2015.02.024

17. Little AS, Kelly DF, White WL, Gardner PA, Fernandez-Miranda JC, Chicoine $\mathrm{MR}$, et al. Results of a prospective multicenter controlled study comparing surgical outcomes of microscopic versus fully endoscopic transsphenoidal surgery for nonfunctioning pituitary adenomas: the Transsphenoidal Extent of Resection (TRANSSPHER) study. J Neurosurg. (2019) 132:1043-53. doi: $10.3171 / 2018.11$.JNS181238

18. Choe JH, Lee KS, Jeun SS, Cho JH, Hong YK. Endocrine outcome of endoscopic endonasal transsphenoidal surgery in functioning pituitary adenomas. J Korean Neurosurg Soc. (2008) 44:151-5. doi: $10.3340 / \mathrm{jkns} .2008 .44 .3 .151$

19. Cheng RX, Tian HL, Gao WW, Li ZQ. A comparison between endoscopic trans-sphenoidal surgery and traditional trans-sphenoidal microsurgery for functioning pituitary adenomas. J Int Med Res. (2011) 39:1985-93. doi: $10.1177 / 147323001103900545$

20. Fathalla H, Cusimano MD, Di Ieva A, Lee J, Alsharif O, Goguen J, et al. Endoscopic versus microscopic approach for surgical treatment of acromegaly. Neurosurg Rev. (2015) 38:541-8; discussion 548-549. doi: 10.1007/s10143-015-0613-7

21. Gao Y, Zheng H, Xu S, Zheng Y, Wang Y, Jiang J, et al. Endoscopic versus microscopic approach in pituitary surgery. J Craniofacial Surg. (2016) 27:e157-9. doi: 10.1097/SCS.0000000000002401

22. Guo-Dong H, Tao J, Ji-Hu Y, Wen-Jian Z, Xie-Jun Z, Jian G, et al. Endoscopic versus microscopic transsphenoidal surgery for pituitary tumors. J Craniofacial Surg. (2016) 27:e648-55. doi: 10.1097/SCS.0000000000003000

23. Starke RM, Raper DM, Payne SC, Vance ML, Oldfield EH, Jane JA. Endoscopic vs microsurgical transsphenoidal surgery for acromegaly: outcomes in a concurrent series of patients using modern criteria for remission. J Clin Endocrinol Metab. (2013) 98:3190-8. doi: 10.1210/jc.20 13-1036

24. Sarkar S, Rajaratnam S, Chacko G, Chacko AG. Endocrinological outcomes following endoscopic and microscopic transsphenoidal surgery in 113 patients with acromegaly. Clin Neurol Neurosurg. (2014) 126:190-5. doi: 10.1016/j.clineuro.2014.09.004

25. Pledger CL, Elzoghby MA, Oldfield EH, Payne SC, Jane JA. Prospective comparison of sinonasal outcomes after microscopic sublabial or endoscopic endonasal transsphenoidal surgery for nonfunctioning pituitary adenomas. $J$ Neurosurg. (2016) 125:323-33. doi: 10.3171/2015.6.JNS142695

26. D'haens J, Van Rompaey K, Stadnik T, Haentjens P, Poppe K, Velkeniers B. Fully endoscopic transsphenoidal surgery for functioning pituitary adenomas: a retrospective comparison with traditional transsphenoidal microsurgery in the same institution. Surg Neurol. (2009) 72:336-40. doi: 10.1016/j.surneu.2009.04.012

27. Gao Y, Zhong C, Wang Y, Xu S, Guo Y, Dai C, et al. Endoscopic versus microscopic transsphenoidal pituitary adenoma surgery: a meta-analysis. World J Surg Oncol. (2014) 12:94. doi: 10.1186/1477-7819-12-94

28. Yu SY, Du Q, Yao SY, Zhang KN, Wang J, Zhu Z, et al. Outcomes of endoscopic and microscopic transsphenoidal surgery on non-functioning pituitary adenomas: a systematic review and meta-analysis. J Cell Med Mol. (2018) 22:2023-7. doi: 10.1111/jcmm.13445

29. Li A, Liu W, Cao P, Zheng Y, Bu Z, Zhou T. Endoscopic versus microscopic transsphenoidal surgery in the treatment of pituitary adenoma: a systematic review and meta-analysis. World Neurosurg. (2017) 101:236-46. doi: 10.1016/j.wneu.2017.01.022

30. Cappabianca P, Alfieri A, Colao A, Ferone D, Lombardi G, De Divitiis E. Endoscopic endonasal transsphenoidal approach: an additional reason in support of surgery in the management of pituitary lesions. Skull Base Surg. (1999) 9:109-17. doi: 10.1055/s-2008-1058157

31. Koc K, Kenan K, Anik I, Ihsan A, Ozdamar D, Dilek O, et al. The learning curve in endoscopic pituitary surgery and our experience. Neurosurg Rev. (2006) 29:298-305; discussion 305. doi: 10.1007/s10143-006-0033-9

32. Leach P, Abou-Zeid AH, Kearney T, Davis J, Trainer PJ, Gnanalingham KK. Endoscopic transsphenoidal pituitary surgery: evidence of an operative learning curve. Neurosurgery. (2010) 67:1205-12. doi: 10.1227/NEU.0b013e3181ef25c5

Conflict of Interest: The authors declare that the research was conducted in the absence of any commercial or financial relationships that could be construed as a potential conflict of interest.

Copyright (C) 2021 Guo, Wang, Kang, Xin and Li. This is an open-access article distributed under the terms of the Creative Commons Attribution License (CC BY). The use, distribution or reproduction in other forums is permitted, provided the original author(s) and the copyright owner(s) are credited and that the original publication in this journal is cited, in accordance with accepted academic practice. No use, distribution or reproduction is permitted which does not comply with these terms. 